\title{
Sliding across a cytoskeletal milestone
}

Several of the seminal experiments that have shaped cell biology today are now reaching a grand age worthy of reflection. Last year, scientists around the globe toasted 50 years of the DNA double helix. Earlier this year marked an event of arguably equal significance: 60 years since the discovery of DNA as the unit of genetic information in Pneumococcus. This month, it is the sliding marriage between myosin and actin that celebrates its golden anniversary.

In May 1954, two milestone studies published in Nature (173, 971 and 973 ; 1954) made the key observations that subsequently led two independent groups, Andrew Huxley with R. Niedergerke, and Hugh Huxley with Jean Hanson, to formulate the 'sliding filament' hypothesis of muscular contraction - the proposal that muscle contraction is triggered by the movement of actin- and myosin-based filaments relative to each other (Huxley, H. E. Science 164, 1356; 1969). It was the initial microscopy studies of the changes occurring in the muscle banding patterns during the contraction process that formed the basis for this model.

The reverberations of these studies have led to a new wave of cell biology and have precipitated our current knowledge not only of muscle contraction (see also Nature Rev. Mol. Cell Biol. 2, 387; 2001) but also of the ways in which motor proteins drive transport and morphogenetic movements in almost every cell type. One key event triggered by the desire to understand the crossbridge cycle of myosin was the development in the 1980s of quantitative in vitro motility assays, which allowed measurement of the ATP-dependent movement of myosin along actin, and incidentally also resulted in the identification of myosin's 'mirror' - the kinesin motors that direct transport along microtubules. Over the decade that followed, these studies evolved to allow the analysis of single motor molecules, and the concept that they move by nanometre steps exerting piconewton forces.

Of course, as our knowledge increases, actin filaments are becoming ever more crowded. In 1973, Tom Pollard and Edward Korn showed that there was more than one type of myosin found in non-muscle cells (J. Biol. Chem. 248, 4682). We now know that there are more than 40 unique myosins in mammals. Among them are motors that move in different directions and with different kinetic and physical properties along actin, including processive movement. We have further learnt that myosins drive processes as diverse as cytokinesis, cell movement, and trafficking events such as endocytosis. Although myosins are among the best understood enzymes today, we still have much to learn about their cellular life. Not least of which, how do particular myosins bind to their receptors at the right place in the cell and how do they work together in certain situations? What determines the direction of movement and the characteristics of a particular myosin's motility? The term 'unconventional' — originally applied to all myosins discovered since myosin II — no longer seems to apply, as it is less clear now what constitutes 'normal' motor behaviour.

To mark this occasion, Nature has put together a special web focus site (available at www.nature.com/nature/focus/slidingfilaments, later this month), which hosts the original reports of sliding filaments together with key Nature papers published on myosin each decade since, accompanied by editorial summaries, and a link to an animation of the process itself. Celebrations will abound this month: two meetings dedicated to the topic of myosin and muscle are to be held in London by The Royal Society and by King's College London. At Nature Cell Biology we look forward to the next chapter on myosin cell biology and welcome your contributions in this golden era of myosin.

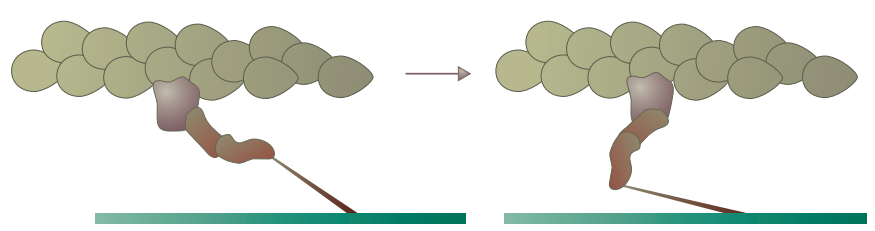

\section{Vive la resistance!....}

...at least that's what many researchers in France must have felt, after president Jacques Chirac conceded on April 1st that the mass protests of the grassroots Save Research movement over substantial job and budget cuts were justified. This was preceded by the re-appointment of François Fillon as minister of education and research, and François d'Aubert as junior minister of research. These concessions were precipitated by the temporary resignation of several thousand senior scientists, as well as widespread media coverage and public support, and there have already been real moves to meet some of the protesters' demands.

However, the French research landscape is still locked in a largely antiquated system. Although there has already been a marked move away from French as the primary language of scientific communication, too many positions and research projects remain largely immune from truly independent assessment. Academic hierarchies can still stifle independent research by young researchers. The re-instatement of 550 permanent research posts and the commitment to create over 1,000 new university positions is a laudable move that will bolster research in France; however, it will also be important for the Save Research movement to maintain its momentum and to find consensus on more controversial aspects of science policy, such as lifetime positions awarded to a subset of junior researchers.

Nevertheless, credit to the French government for entering into active dialogue with the scientific community - let's hope that their ears remain open without the need to resort to stifling protests, and lets see whether governments of other countries facing protests by academics and students, such as the UK and Italy, will be similarly receptive to dialogue. 